
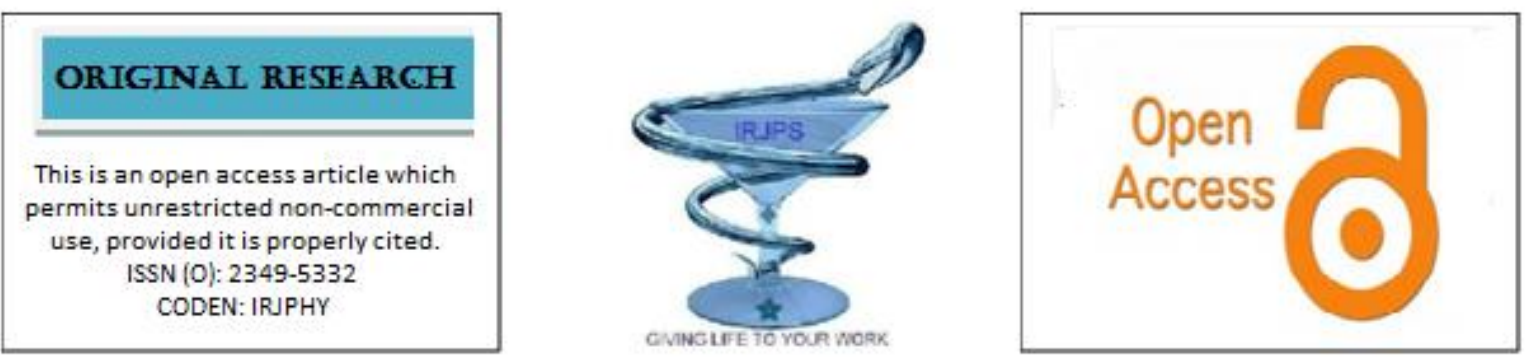

\title{
ARE ANTIBIOTICS PRESCRIBED APPOSITELY FOR EXIGENCY TREATMENT IN CHENNAI CITY REGION, INDIA
}

\author{
SWARUPA K B, SUGANYA P, PRABU D, SUNAYANA, RAJMOHAN,
}

SRM Dental College, Ramapuram.

\section{Submitted on: 18.08.19;}

Revised on: 28.08.19;

Accepted on: 01.09.19

\begin{abstract}
:
Objectives: To study the therapeutic prescribing pattern to patients with dental exigency.

Materials and Methods: Prospective study was conducted among 300 dental clinics in Chennai city out of which 500 adult patients and 135 child patients' details were recorded. The Study was done, where there was a maximum number of patients visiting clinics per day, during particular timings. Hospitals, dental institutions, and other private dental emergency clinics were visited and details of the patients were analyzed and recorded.

Results and conclusion: Mostly the patients who attended the dental clinic had pain issued with prescriptions for antibiotics. The principle antibiotic issued for all age group patients is amoxicillin. The study shows that the majority of patients visited the emergency dental clinic had pain and localized infection. Three quarters did not have surgical therapy and were prescribed antibiotics inappropriately.
\end{abstract}

KEYWORDS: Antibiotics, prescriptions, dental exigency, dental clinic

Corresponding author: Suganya $P$

E-mail: suganyasugan772@gmail.com

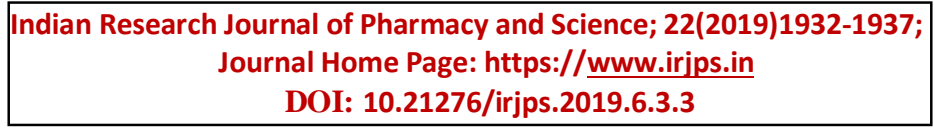




\section{INTRODUCTION}

The first invented antibiotics are penicillin and have been used to treat many infections. Antibiotics have managed and cured many fatal conditions. But the problem arises with an antibiotic overuse which causes infection. Some bacteria such as MRSA (Methicillin-resistant staph aureus) cause drug resistance. Recently, $33^{\text {rd }}$ annual convention of the Philippine Society of microbiology and infectious diseases, doctors and medical experts had concluded that the misuse of antibiotics causes "infectious superbugs" 1

Now adays many research have been performed to enlighten the knowledge and helps to change the attitude towards practice and treatment. Dental professionals should give proper care and treatment for exigency patients like an acute spread of infection, hemorrhage, trauma, swelling within a short period of time. Antibiotics can inhibit or kills microorganisms even at the concentration of a very low level. The treatment for acute infections depends upon the condition of the teeth and pulp extirpations 2. Antibiotics are used for any orofacial infections. But some antibiotics may produce allergic reactions, side effects and some may develop resistance to certain strains of bacteria. Antibiotic overdose causes resistance to strains of bacteria. About $1 / 3 \mathrm{rd}$ of the medicines were used for prophylactic needs. ${ }^{3}$

According to Thomas et al.; investigated the antibiotics prescribed for patients with exigency dental care by primary healthcare workers. ${ }^{4}$

In the year 1997, GDP provided $£ 5.2$ million costs for 3.5 million antibiotic prescriptions. ${ }^{5}$ This prospective clinical study aims to investigate the appropriateness of prescription of antibiotics for exigency care.

\section{MATERIALS AND METHODS}

A prospective study was conducted over a period of 1month from December 2011 to January 2012. Since this is a short study IRB is not required clinical approval obtained from the Department of Public Health Dentistry, SRM dental college, Ramapuram. Certain selected hospitals and dental clinics in the Chennai region were investigated among 300 dental clinics in Chennai city approximately where the population is around 4.6 million. Out of which 500 adult patients and 135 child patients' details were recorded. The Study was done, where there was a maximum number of patients visiting clinics per day, during particular timings. Hospitals, dental institutions, and other private dental emergency clinics were visited and details of the patients were analyzed and recorded. These places were chosen according to the lottery method and sampling method.

\section{Data collection}

Information was recorded regarding patients attending a clinic (emergency) and treatment underwent. At first, the demographic details of the patient which included name, age, sex address, phone no: was taken from the clinics.

The patient complaints and treatment provided was recorded by using questionnaire and filled by dentists. The pain, swelling, cavity, bleeding, trauma, etc are the complaints. The $3^{\text {rd }}$ part of the questionnaire included the characteristic of pain, swelling, type of bleeding and trauma.

The next questionnaire included the patient $1 \mathrm{~s}$ with other emergencies and diagnosis for the complaint presented. The questionnaire also included the treatment provided. The last part included the type of antibiotic prescribed for the patients who came with emergencies.

The samples were selected from health authorities among different parts of Chennai including Vadapalani, Porur, Ramapuram, KK Nagar, Ashoknagar, Thiruvanmiyur, etc.

The questionnaire obtained was recorded and updated into the statistical page for social sciences (SPSS) version 9 and calculated.Frequencies, percentages, means and standard deviations where indicated.

\section{RESULTS}

In this study, around 25 dentists were worked in the dental clinic (emergency) around 10.00am to $7.00 \mathrm{pm}$. Of that 14 dentists were male and 11 were female. Their mean age was 35 years and range (25-56). Totally 600 patients attended dental clinics during the 
study period.85 questionnaires were not filled and 560 out of 600 copies were analyzed.

\section{Statistical analysis}

The mean value for the patients who attended clinics was 12 and their range was 10-40. About 300 male patients and 215 female patients were present. Of that $4 \%$ of patients attended the clinics other than emergencies like lost of crowns, bridges or dentures, etc.

Reason for patients attending dental clinic

Table 1: clinical signs and symptoms of patients attending an emergency dental clinic

\begin{tabular}{|c|c|c|c|c|}
\hline \multirow{2}{*}{$\begin{array}{c}\text { SIGNS AND } \\
\text { SYMTOMS }\end{array}$} & \multicolumn{2}{|c|}{$\begin{array}{c}\text { ADULT } \\
\text { PATIENTS }\end{array}$} & \multicolumn{2}{c|}{ CHILD } \\
\cline { 2 - 5 } & $\mathbf{N}$ & $\%$ & $\mathbf{N}$ & $\%$ \\
\hline Pain & 382 & $74 \%$ & 103 & $76 \%$ \\
\hline Localized swelling & 100 & $19 \%$ & 26 & $19 \%$ \\
\hline Lost Restorations & 8 & $2 \%$ & 2 & $1 \%$ \\
\hline Cavities / fracture & 25 & $5 \%$ & 4 & $3 \%$ \\
\hline Gingival bleeding & 16 & $3 \%$ & 1 & $0.5 \%$ \\
\hline Trauma & 1 & $0.2 \%$ & 5 & $4 \%$ \\
\hline Others & 28 & $4 \%$ & 2 & $1 \%$ \\
\hline Total & 560 & $100 \%$ & 144 & $100 \%$ \\
\hline
\end{tabular}

Table 1 shows the cause for attending emergency dental clinics. 382 patients (adult 74\%, children 76\%) attended the emergency clinics with pain. Some of the patients were also presented with other signs and symptoms. 100 patients (adult: 100/560, 19\%, children: 26/144, $19 \%$,) had presented with swelling. Around 8 adults had lost restorations. 25 adult patients with cavity fractures, $3 \%$ came with gingival bleeding, $0.2 \%$ had trauma, and others with bleeding of the socket

TABLE 2: Clinical diagnosis of prescribed antibiotics for patients with pain

\begin{tabular}{|l|c|c|c|c|}
\hline \multirow{2}{*}{ Diagnosis } & \multicolumn{2}{|c|}{ ADULT PATIENTS } & \multicolumn{2}{c|}{ CHILD PATIENTS } \\
\cline { 2 - 5 } & $\begin{array}{c}\text { Number } \\
\text { with Pain }\end{array}$ & $\begin{array}{c}\text { Number } \\
\text { prescribed } \\
\text { antibiotics }\end{array}$ & $\begin{array}{c}\text { Number } \\
\text { with Pain }\end{array}$ & $\begin{array}{c}\text { Number of } \\
\text { prescribed } \\
\text { antibiotics }\end{array}$ \\
\hline Pulpitis & 269 & 80 & 77 & 18 \\
\hline $\begin{array}{l}\text { Dentoalveol } \\
\text { ar abscess }\end{array}$ & 33 & 53 & 7 & 7 \\
\hline $\begin{array}{l}\text { Periapical } \\
\text { Infection }\end{array}$ & 49 & 5 & 13 & 2 \\
\hline Trauma & 4 & 1 & 3 & 1 \\
\hline Others & 28 & 12 & 5 & 4 \\
\hline $\begin{array}{l}\text { Unable to } \\
\text { Diagnose }\end{array}$ & 7 & 7 & 1 & 1 \\
\hline Total & $\mathbf{3 8 4}$ & $\mathbf{1 5 8}$ & $\mathbf{1 0 6}$ & $\mathbf{3 4}$ \\
\hline
\end{tabular}




\section{OBSERVATIONS}

Table 1 and 2 shows the treatment given to patients attending emergency clinics. 154 adults and 32 children patients had issued the only prescription at the emergency clinics. 58 percent of adults and $62 \%$ of children had received antibiotics.

$4 \%$ of adults and children patients had undergone extraction without a prescription issued. Adult patients were incised swelling of endodontic treatment. Dressings were done for lost restorations, dry sockets, and fracture of the tooth. Around 60 adults obtained various treatments included reestablishing crowns and bridges, curettage of pericoronitis. 2 of them were taken to the hospital for undergoing surgical procedure one including a fracture of mandible and other for excision due to some pathological condition.

\section{Antibiotics prescribed for pain:}

Pulpitis and the dentoalveolar abscess was the cause of pain in most of the child patients $(84 / 103,82 \%)$, the antibiotic prescription was received by threequarter children $(25 / 116,22 \%)$. Half number of adult patients had attributed with pain $(302 / 384,78.6 \%)$, of that nearly half patients received an antibiotic prescription $\quad(133 / 384$,

$35 \%)$

TABLE 3: PRESCRIBED ANTIBIOTICS

\begin{tabular}{|l|c|c|}
\hline \multicolumn{1}{|c|}{ Antibiotics } & \multicolumn{1}{c|}{$\begin{array}{c}\text { Number of } \\
\text { patients receiving } \\
\text { antibiotics }\end{array}$} & $\begin{array}{c}\text { Percentage of a } \\
\text { prescription } \\
\text { issued }\end{array}$ \\
\hline Amoxicillin & 298 & $46 \%$ \\
\hline $\begin{array}{l}\text { Amoxicillin and } \\
\text { Metronidazole }\end{array}$ & 191 & $29 \%$ \\
\hline Metronidazole & 49 & $8 \%$ \\
\hline Penicillin v & 23 & $4 \%$ \\
\hline Erythromycin & 10 & $2 \%$ \\
\hline $\begin{array}{l}\text { Erythromycin with } \\
\text { metronidazole }\end{array}$ & 33 & $5 \%$ \\
\hline Others & 46 & $7 \%$ \\
\hline
\end{tabular}

Table 3 shows the frequency of antibiotics prescribed. Amoxicillin was the commonly prescribed antibiotic (46\%)for all patients. Only adult patients were prescribed a combination of metronidazole and amoxicillin: 191(29\%). Totally $(8 \%)$, adults were prescribed metronidazole only

\section{DISCUSSION}

The study investigated the appropriate use of antibiotics in dentistry. About $70 \%$ of the questionnaires were returned completed. The questionnaire included the demographic details of the patient and swelling, lost restorations, trauma, cavities, gingival diseases, etc. It was found in the due course of time of study that levels of prescription of antibiotics could be affected by varying dental emergency and services the patient is presenting.
Moreover, the results of the questionnaire studies state that basic principles for prescribing antibiotics are getting ignored and prescribed without proper protocol.

Most often the patients came with pain as their major emergency, three quarter adult patients and almost all child patients were presented with a localized infection like an abscess, pulpitis. Antibiotics are prescribed for all patients with pulpitis. Ibuprofen was also prescribed frequently medication for pain, and penicillin was also frequently prescribed with patients with an active infection. ${ }^{6,7}$ Drugs only provide symptomatic relief and do not complete relief so the infection may get progress. The 3D principle was used by dental professionals to manage pain. The dentists should emphasis the diagnosis properly to 
provide effective treatment. In some situations, exigency treatment is required to prevent mortality. ${ }^{8}$ Antibiotics should not be prescribed in non-chronic infections ${ }^{9}$. The most commonly prescribed antibiotics are amoxicillin, which was given alone or combined with metronidazole. Around 100 adult patients came with localized swelling. But the patients should be monitored if the antibiotics are prescribed without drainage. ${ }^{10}$

The reason behind Practitioners prescribing antibiotics inappropriately is not known this might be due to poor knowledge of using antibiotics. ${ }^{11}$ Dental practitioners may have a poor understanding of the pathology behind pulp and periapical diseases. However, some studies show that $50 \%$ of antibiotics were prescribed non-emergency consultations causes infection in $25 \%$ cases ${ }^{12}$. It is known that in emergency clinics the role of appointment facility is absent and a large number are seen in succession. This may create difficulty to make a proper diagnosis, limitations in the treatment provided. Especially time-consuming procedures like a periodontal abscess, dry socket, and periodontal surgery might be treated efficiently using local treatments whereas antibiotics are prescribed for large chronic infections ${ }^{13}$. Amoxicillin and Metronidazole were routinely prescribed. In majority situations, antibiotics were prescribed for avulsed tooth re-implantation ${ }^{14}$. Recent studies have shown that antibiotics do not affect the clinical duration of disease ${ }^{15}$. How can we prevent this? What is the way to pull forward? Qualitative research has to be done to find out from the dental professionals why this problem of prescribing inappropriately is so out of track. One such method is an audit. Antibiotics prescribing are being subjected to most of the audits ${ }^{16}$. Among these audits, one was conducted in the year 1997 by steed and colleagues 17. The antibiotics misusage was one of the biggest issues to solve and it requires an intersectoral solution. ${ }^{18}$ Many programs and campaigns related to drug interventions must be ensured to overcome the misusage and drug resistance. Besides, there are certain guidelines proposed for the proper use of antibiotics published by the General practice in Ireland. ${ }^{19}$ Another guideline was developed in the year of 2001 by guide to development practice. ${ }^{20}$ The rationale for the use of antibiotics appropriately has to be looked on before starting and prescribing of medicines by all physicians and dental professionals. Thus appropriate use of antibiotics is necessary for emergency dental treatment.

\section{CONCLUSION:}

Most often the patients visited the dental clinic (emergency) had reported pain (269/384) with a localized infection like pulpitis or dental abscess with very little showing symptoms of spreading infections. Almost $3 / 4^{\text {th }}$ of patients were prescribed with antibiotics and no surgical treatment for pulpitis. Hence this study supports that the antibiotics were prescribed improperly by dental professionals in case of emergencies.

\section{REFERENCES:}

1. Theresa $\mathrm{S}$ Samaniego, Improper use of antibiotics may lead to the evolution of infectious superbugs Philippine daily Linquirer sat December 10 $0^{\text {th }}, 2011$.

2. Olson AK, Mac Edington E, Kulid JC, Weller RN.Update on antibiotics for endodontic practice. Compend Continuing Educ Dent 1995; 11: 328-332.

3. Neu HC. Prophylaxis - has it at last come of age J Antimicrob Chemother 1979;5:331-3

4. Thomas DW, Satterthwaite J, Absi EG Lewis MAO, Sheperd JP. Antibiotic prescription for acute dental conditions in the primary care setting. Br. Dent $J$ 2000;188:401 -404

5. Prescription cost analysis system. Dental practitioner prescribing-antimicrobials. Department of Health, Statistics Division IE, 1998.

6. Ulibau IC, Jaunay T. Goss AM Severe odontogenic infections - Aust Dent J 2005;50 (4 supplements 2): s 74-s 81

7. Abbolt PV, Hume WR, Pearman JW. Antibiotics and endodontic. Aust Dent J 1990;35: 50- 60

8. Current trends in Endo practice: Emergency Treatments and Technology Armamentarium. Michelle Lee,DDS,Jonathan, Winkler,DDS, Gary Hartwell,DDS.MS,Jefferey Stewart ,DMD and Rufus Canin DDS 
9. Martin MV, Longman LP.Hill JB, Hardy P.Acute dentolveolar infections: an investigation of the duration of antibiotic therapy. BR.Dent J 1997 183:135-137

10. Palmer NAO,Pealing,Ireland RS.Martin MV, A study of therapeutic antibiotic prescribing in national health services general dental practices in England .BR.Dent J 2000 ; 188;554-558

11. Liss RH, Batchelor FR. Economic Evaluation of antibiotic use and resistance - a perspective report of task force 6 RID May June 1987;9(supplements 3): s 297-s 312

12. Fazakerlay MW, McGowan P,Hardy P, Martin MV A comparative study of cephridine ,amoxicillin, and phenoxymethyl penicillin in the treatment of acute dentoalveolar infection. $B r$ Dent $J$ 1993;174:359-363

13. Gill Y, Scully C, Orofacial odontogenic infections: review of microbiology and current treatment. Oral surg oral med oral pathol 1990;70:155-8

14. Trope M.Clinical management of the avulsed tooth. Dent Clin North America 1995;39:93-112
15. Van Buchem FL, Knottnerus JA, Schinjeemaekers VJ, Peeters MF Primary care based randomized placebo controlled trial of antibiotics treatment in acute maxillary sinusitis. . Med J Aust 1994;160:502-504

16. De Santis G, Harvey KJ, Howard D, Mashford ML, Moulds RF. Improving the quality of antibiotic prescription patterns in general practice. The role educational intervention. Med J Aust 1994;160:502-504

17. Swann RA, Clark J. Antibiotic policiesrelevance to general practitioner prescribing. Family Health Services Authority, Great Britian. $J$ Antimicrobials Chemother 1994;4:66-70

18. Edwin K DY, MD Inappropriate Antibiotic Use in the Phillippines.Senior Research Specialist 2 Emmanuel Phillippine, Australia. Cooperation Project on National drug policy

19. Antibiotic prescribing guidelines for general practice in Ireland,Dr. Brian Carey, HSE SE Regional department of antibiotic medicine, Ireland

20. Guide to development of practice guidelines ,IDSA CID 1 2001;32:851-4 